\title{
First Isolation of Candida nivariensis, an Emerging Fungal Pathogen, in Kuwait
}

\author{
Khaled Alobaid $^{\mathrm{a}} \quad$ Mohammad Asadzadeh $^{\mathrm{b}} \quad$ Ritu Bafna $^{\mathrm{c}} \quad$ Suhail Ahmad ${ }^{\mathrm{b}}$ \\ ${ }^{a}$ Mycology Laboratory, Mubarak Al-Kabeer Hospital, Jabriya, Kuwait; ${ }^{b}$ Department of Microbiology, \\ Faculty of Medicine, Kuwait University, Jabriya, Kuwait; ${ }^{C}$ Microbiology Unit, Medical Laboratory Department, \\ Sabah Hospital, Shuwaikh, Kuwait
}

\section{Highlights of the Study}

- Candida nivariensis is an emerging fungal pathogen which is often misidentified by conventional phenotypic methods.

- Molecular testing or MALDI-TOF MS with updated software is required to accurately detect C. nivariensis.

- The first clinical C. nivariensis isolate from Kuwait exhibited high MIC against fluconazole, a commonly used antifungal drug.

- Accurate identification and antifungal susceptibility testing are essential for the treatment of infections caused by rare yeast pathogens.

\section{Keywords}

Candida nivariensis - Rare yeasts - Matrix-assisted laser desorption ionization-time of flight mass spectrometry . Antifungal resistance $\cdot$ Kuwait

\footnotetext{
Abstract

Objective: $C$. nivariensis is a rare Candida species which is phenotypically closely related to Candida glabrata and Candida bracarensis. The 3 species form the C. glabrata sensu lato complex. Here, we describe the first isolation and characterization of a C. nivariensis isolate cultured from the tracheal aspirate obtained from a young man in Kuwait. Materials and Methods: The yeast isolate was initially tested by VITEK 2 followed by matrix-assisted laser desorption ionizationtime of flight mass spectrometry (MALDI-TOF MS) and multiplex PCR. The identification was confirmed by sequencing of internal transcribed spacer (ITS) region of rDNA. Antifungal susceptibility testing was performed by Etest, and phylo-
}

genetic comparison with other international strains was carried out by using MEGA version 7 software. Results: The $C$. nivariensis isolate was misidentified by VITEK 2, but correctly identified by MALDI-TOF MS with updated software and multiplex PCR. The identity was confirmed by sequence comparisons of ITS region of rDNA. Antifungal susceptibility testing revealed high minimum inhibitory concentration (MIC) against fluconazole, but low MICs against amphotericin B and echinocandins. Phylogenetically, our isolate was closely related to Indian isolates. Conclusions: This report extends the geographic distribution of $C$. nivariensis to the Arabian Peninsula. MALDI-TOF MS with updated software and molecular tests are needed to correctly identify C. nivariensis. Since $C$. nivariensis may exhibit reduced susceptibility to antifungal agents, accurate identification and antifungal susceptibility testing are essential, particularly for isolates from sterile sites, for optimal patient management.

(c) 2020 The Author(s)

Published by S. Karger AG, Basel
C) 2020 The Author(s)

Published by S. Karger AG, Basel

This is an Open Access article licensed under the Creative Commons Attribution-NonCommercial-4.0 International License (CC BY-NC) (http://www.karger.com/Services/OpenAccessLicense), applicable to the online version of the article only. Usage and distribution for commercial purposes requires written permission.
Khaled Alobaid

Mycology Laboratory, Medical Laboratory Department

Mubarak Al-Kabeer Hospital

Street 103, Jabriya 46300 (Kuwait)

khaled22m@live.com 


\section{Introduction}

Candida nivariensis is a rare Candida species which belongs to the Nakaseomyces clade. Phylogenetically, it is closely related to Candida glabrata, Candida bracarensis, and nonpathogenic Nakaseomyces delphensis[1]. C. nivariensis was first described in Spain in 2005. It was isolated from 3 different clinical samples during the period 1999-2002 [2]. Subsequently, this species was identified among clinical isolates of C. glabrata sensu lato, which includes C. glabrata sensu stricto, C. nivariensis, and C. bracarensis, mostly by the application of molecular methods in various countries across the world including Japan, UK, USA, Indonesia, Malaysia, India, China, Australia, Italy, Poland, Iran, Egypt, Brazil, and Argentina [3-15]. C. nivariensis has been implicated in different types of infections including invasive infections such as candidemia, peritonitis, and pelvic abscess $[4,8,12]$. It has also been implicated in mucocutaneous infections such as vulvovaginal candidiasis and oropharyngeal candidiasis $[5,16]$. Accurate identification of $C$. nivariensis by commonly used phenotypic methods in routine clinical microbiology laboratories is difficult as it is usually misidentified [2]. C. nivariensis strains isolated from clinical specimens often exhibit reduced susceptibility to commonly used antifungal drugs [2-4]. Here, we describe the first isolation and characterization of $C$. nivariensis from a clinical specimen indicating the emergence of this species in Kuwait. We also briefly discuss the laboratory diagnostic methods for accurate species-specific identification and compare antifungal drug susceptibility patterns among clinical C. nivariensis isolates from other geographical locations within the Middle East and India.

\section{Materials and Methods}

\section{Case Description}

A 35-year-old Kuwaiti male was brought to the Medical Casualty Department of Mubarak Al-Kabir Hospital because of generalized tonic-clonic convulsions, vomiting, and aspiration. He was previously diagnosed with epilepsy but was noncompliant with his medication. On arrival, the patient received diazepam, was intubated, and shifted to intensive care unit (ICU). During his ICU stay, blood, tracheal aspirate, and urine samples were collected for culture. The patient was treated with ceftriaxone, which was later switched to meropenem and vancomycin. The tracheal aspirate culture grew a yeast, while other cultures were negative. Five days later, the patient became afebrile, was extubated, and his antibiotic therapy was discontinued. He did not receive any antifungal therapy.

Emergence of C. nivariensis in Kuwait
Mycological Workup and Antifungal Susceptibility Testing

The yeast isolate was subcultured on Sabouraud dextrose agar and CHROMagar chromogenic media (CHROMagar, Paris, France) according to the manufacturer's instructions and as described previously [17]. VITEK 2 and VITEK MS (bioMérieux) were used for species identification, and antifungal susceptibility testing was performed by Etest (bioMérieux) according to the manufacturer's instructions and as described previously [18, 19].

\section{PCR and DNA Sequencing}

To confirm the species identification, molecular testing was performed. Genomic DNA was extracted from the isolate by the rapid boiling method using Chelex 100, as described previously [20]. Subsequently, multiplex PCR (mPCR) was performed using mCGLF, mCNIF, mCBRF, and mCGCR primers which yields amplicons of $\sim 360 \mathrm{bp}, \sim 288 \mathrm{bp}$, and $\sim 299 \mathrm{bp}$ from C. glabrata sensu stricto, C. nivariensis, and C. bracarensis, respectively [21]. PCR amplification results were confirmed by DNA sequencing of the internal transcribed spacer (ITS) region of rDNA using panfungal primers, as described previously [22].

\section{Phylogenetic Comparisons}

The genotypic relationship of our isolate with some other previously described strains was analyzed. The ITS region sequence was compared with the corresponding sequences from 13 C. nivariensis isolates retrieved from GenBank. Pairwise comparisons and multiple sequence alignments were performed with MUSCLE (https://www.ebi.ac.uk/Tools/msa/muscle/) [23]. Phylogenetic tree was constructed by employing the MEGA (https://www. megasoftware.net/) software version 7 [24] using the neighborjoining method, and the robustness of tree branches was assessed by bootstrap analysis with 1,000 replicates, as described previously [20].

\section{Results}

The yeast isolate (Kw261-1/20) produced creamy colored colonies on CHROMagar medium. VITEK 2 and VITEK MS with updated database identified the isolate as Candida magnoliae with a score of $97 \%$ and C. nivariensis with a score of $99.9 \%$, respectively. The mPCR amplification yielded an amplicon of $\sim 288 \mathrm{bp}$ which is a characteristic of $C$. nivariensis. Furthermore, basic local alignment search tool (BLAST) searches (http://www.ncbi.nlm.nih. gov/BLAST/Blast.cgi) [25] of DNA sequence data for the ITS region of our isolate showed $>99 \%$ identity with reference strains of C. nivariensis (CBS 9983 and CBS 10161 corresponding to GenBank Accession No. MH545923 and GU199441, respectively). Based on the previous observations that fungal strains belonging to the same species exhibit $>99 \%$ nucleotide identity in the ITS region of rDNA [26], the molecular identity of our isolate (Kw261$1 / 20$ ) was established as $C$. nivariensis. Multiple sequence alignment was carried out to compare the genotypic rela- 
Fig. 1. Neighbor-joining phylogenetic tree based on sequence data for the ITS region of rDNA for Kw261-1/20 (GenBank Accession No. LR792666) together with 13 other C. nivariensis isolates. The GenBank Accession No./Isolate No. and the country of isolation/Strain No. for reference strains are shown. The countries are abbreviated as AR, Argentina; CN, China; IN, India, IR, Iran; MY, Malaysia; SP, Spain; and USA, United States of America. The bootstrap frequencies $(>50 \%)$ on the node branches are also shown. ${ }^{*}$ CBS9983, Iran; CBS9985, Iran; CBS10161, Indonesia. ITS, internal transcribed spacer.

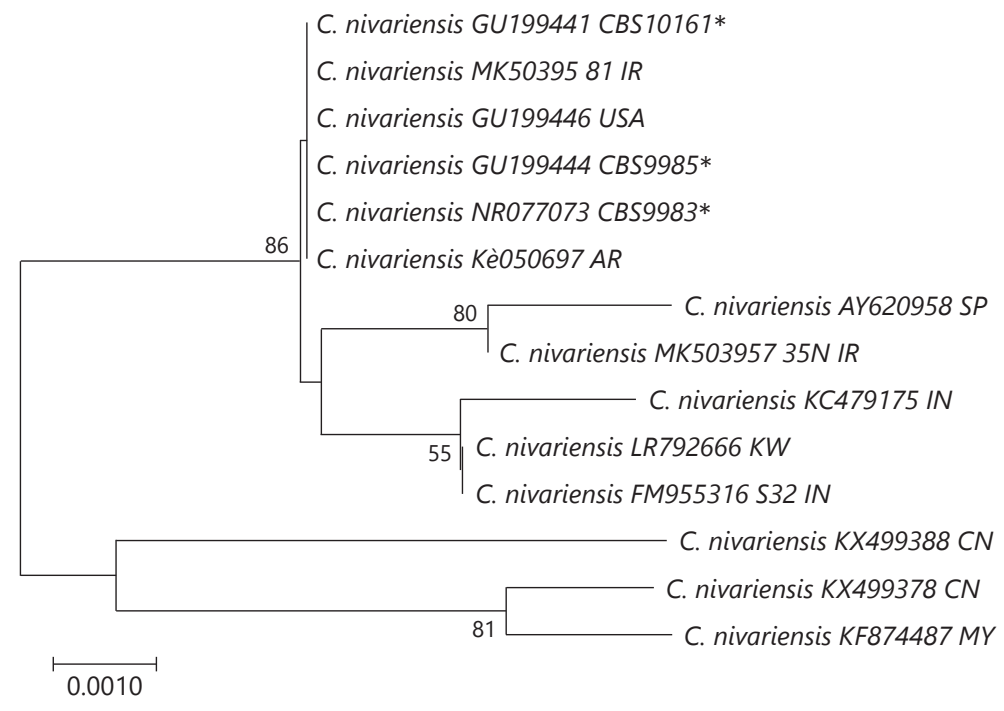

tion of C. nivariensis from a clinical specimen in Kuwait. The isolate was recovered from a nonsterile site, and the patient's condition improved without any antifungal treatment suggesting mere colonization of the patient with C. nivariensis. The origin of C. nivariensis in Kuwait remained uncertain as the travel history of the patient was not available. The present report extends the geographic distribution of this emerging fungal pathogen to the Arabian Peninsula as no similar cases have previously been reported from other countries in this region.

Although C. nivariensis was discovered nearly 15 years ago [2], the number of total cases is still relatively small. The true prevalence, however, might be underestimated because the biochemical testing methods currently in use in most clinical laboratories fail to identify rare yeast species, including C. nivariensis, accurately [27]. C. nivariensis shares many phenotypic characteristics with C. glabrata including the inability to form germ tube, pseudohyphae, chlamydospore, or ascospores. However, in chromogenic CHROMagar Candida, the colonies of $C$. glabrata are purple, while C. nivariensis and C. bracarensis form white/cream-colored colonies [2]. Furthermore, in commercial tests based on biochemical utilization of different compounds such as AuxaColor2 and API 20C systems, C. nivariensis assimilates only glucose among carbohydrates in contrast to C. glabrata which can assimilate glucose and trehalose [4].

Currently, the method of choice for detecting C. nivariensis among yeast isolates is application of PCR-based 
Table 1. Comparison of antifungal susceptibility patterns of C. nivariensis isolates from Kuwait, other Middle Eastern countries, and India*

\begin{tabular}{llcccccrrr}
\hline Country & Isolates, $n$ & Amphotericin B & Fluconazole & Itraconazole & Voriconazole & Caspofungin & Anidulafungin & Micafungin & References \\
\hline India & 2 & 0.5 & $1-2$ & 0.25 & 0.03 & - & - & - \\
India & 4 & $0.03-0.125$ & $0.5-16$ & $0.03-0.5$ & $0.03-0.5$ & $0.25-0.5$ & $0.06-0.125$ & 0.015 \\
Iran & 4 & $0.5-1$ & $0.06-1$ & $\leq 0.016-0.06$ & $\leq 0.016-0.03$ & - & $\leq 0.016$ & $\leq 0.016$ & {$[16]$} \\
Egypt & 3 & $0.25-1$ & 16 & 0.5 & - & - & - & - & {$[12]$} \\
Kuwait & 1 & 0.25 & 6 & 1 & 0.125 & 0.19 & 0.032 & 0.006 & Present study \\
\hline
\end{tabular}

* The isolate from Kuwait was tested by Etest, while all other isolates were tested by the broth microdilution method.

methods [21, 29-31] or PCR sequencing of the ITS and/ or D1/D2 domains of rDNA [21,26]. Besides PCR-based methods, matrix-assisted laser desorption ionizationtime of flight mass spectrometry (MALDI-TOF MS) with an updated database has also been shown to accurately detect C. nivariensis $[12,32]$. In this study, C. nivariensis was accurately detected by VITEK MS since the database was updated recently.

C. nivariensis isolates exhibit variable susceptibility to azole antifungal agents. In the case report from Japan, the isolate was resistant to fluconazole and voriconazole with minimum inhibitory concentrations (MICs) of $\geq 128$ and $4 \mu \mathrm{g} / \mathrm{mL}$, respectively [3]. Borman et al. [4] also reported similar findings from UK with $\mathrm{MIC}_{90}$ of $>64$ and $4 \mu \mathrm{g} / \mathrm{mL}$ for fluconazole and voriconazole, respectively. However, a study from China reported lower MICs against fluconazole $\left(\mathrm{MIC}_{90}: 2 \mu \mathrm{g} / \mathrm{mL}\right.$ ) and voriconazole $\left(\mathrm{MIC}_{90}: 0.06\right.$ $\mu \mathrm{g} / \mathrm{mL}$ ) but elevated amphotericin B $\mathrm{MIC}_{90}$ of $2 \mu \mathrm{g} / \mathrm{mL}$ among 12 C. nivariensis isolates [8].

A recent study from UK used the CLSI method and showed that resistance rates against fluconazole, itraconazole, voriconazole, and posaconazole were detected in $30,14.8,51.4$, and $7.7 \%$ of isolates, respectively. However, no resistance was detected against amphotericin B or anidulafungin [33]. Our isolate also exhibited high MIC against fluconazole (MIC of $6 \mu \mathrm{g} / \mathrm{mL}$ ). The antifungal susceptibility profile of our isolate was compared with $C$. nivariensis isolates from other Middle Eastern countries and India, and the data are presented in Table 1. While the 3 isolates tested from Egypt were resistant to fluconazole with an MIC of $16 \mu \mathrm{g} / \mathrm{mL}$ [13], the Iranian isolates were susceptible to fluconazole (MIC of $0.0625-1 \mu \mathrm{g} / \mathrm{mL}$ ) and voriconazole (MIC of $\leq 0.016-0.03 \mu \mathrm{g} / \mathrm{mL}$ ) [12]. The isolates from India [7, 16] exhibited variable patterns (MIC of $0.5-16 \mu \mathrm{g} / \mathrm{mL}$ ) with some isolate exhibiting susceptibility while others showing resistance to fluconazole (Table 1).

Emergence of C. nivariensis in Kuwait

\section{Conclusion}

C. nivariensis is an emerging opportunistic pathogen that can cause invasive infections and can be resistant to azoles. The true prevalence is still unclear, but seems to be underestimated. The inability of phenotypic methods to accurately identify such potential yeast pathogens clearly indicates the importance of molecular testing including MALDI-TOF MS in the diagnosis of this emerging species. Antifungal susceptibility testing of rare yeast species is also essential for proper patient management and epidemiological surveillance.

\section{Acknowledgements}

The authors are thankful to S. Vayalil for technical support.

\section{Statement of Ethics}

Specific ethical approval for this study was not required as the isolate was sent to the Mycology Laboratory and tested as a routine laboratory service. The data are reported on a deidentified sample, the privacy of the patient was respected, and confidentiality was maintained.

\section{Conflict of Interest Statement}

The authors have no conflicts of interest to declare.

\section{Funding Sources}

The authors did not receive any funding. 


\section{References}

1 Gabaldón T, Martin T, Marcet-Houben M, Durrens P, Bolotin-Fukuhara M, Lespinet O, et al. Comparative genomics of emerging pathogens in the Candida glabrata clade. BMC Genomics. 2013;14:623.

2 Alcoba-Flórez J, Méndez-Alvarez S, Cano J, Guarro J, Pérez-Roth E, del Pilar Arévalo M. Phenotypic and molecular characterization of Candida nivariensis sp. nov., a possible new opportunistic fungus. J Clin Microbiol. 2005; 43(8):4107-11.

3 Fujita S, Senda Y, Okusi T, Ota Y, Takada H, Yamada $\mathrm{K}$, et al. Catheter-related fungemia due to fluconazole-resistant Candida nivariensis. J Clin Microbiol. 2007;45(10):3459-61.

4 Borman AM, Petch R, Linton CJ, Palmer MD, Bridge PD, Johnson EM. Candida nivariensis, an emerging pathogenic fungus with multidrug resistance to antifungal agents. J Clin Microbiol. 2008;46(3):933-8.

5 Wahyuningsih R, SahBandar IN, Theelen B, Hagen F, Poot G, Meis JF, et al. Candida nivariensis isolated from an Indonesian human immunodeficiency virus-infected patient suffering from oropharyngeal candidiasis. J Clin Microbiol. 2008;46(1):388-91.

6 Tay ST, Lotfalikhani A, Sabet NS, Ponnampalavanar S, Sulaiman S, Na SL, et al. Occurrence and characterization of Candida nivariensis from a culture collection of Candida glabrata clinical isolates in Malaysia. Mycopathologia. 2014;178(3-4):307-14.

7 Chowdhary A, Randhawa HS, Khan ZU, Ahmad S, Juneja S, Sharma B, et al. First isolations in India of Candida nivariensis, a globally emerging opportunistic pathogen. Med Mycol. 2010;48(2):416-20.

8 Hou X, Xiao M, Chen SC-A, Wang H, Yu S-Y, Fan $X$, et al. Identification and antifungal susceptibility profiles of Candida nivariensis and Candida bracarensis in a multi-center chinese collection of yeasts. Front Microbiol. 2017;8: 5 .

9 Lockhart SR, Messer SA, Gherna M, Bishop JA, Merz WG, Pfaller MA, et al. Identification of Candida nivariensis and Candida bracarensis in a large global collection of Candida glabrata isolates: comparison to the literature. J Clin Microbiol. 2009;47(4):1216-7.

10 Passera M, Corbellini S, Cavalli G, Vailatil F, Frigerio L, Farina C. Candida nivariensis isolates from a pregnant patient. Molecular identification using sequencing and MALDITOF. Int J Clin Exp Pathol. 2016;9:10774-7.

11 Sikora M, Kuthan R, Piskorska-Malolepsza K, Golas-Pradzynska M, Domański D, Augustynowicz-Kopeć E, et al. Prevalence and antifungal susceptibility of the emerging fungal species, Candida nivariensis, isolated in a teaching hospital in Poland. Pol J Microbiol. 2019;68(3):303-8.
12 Arastehfar A, Daneshnia F, Salehi MR, Zarrinfar $\mathrm{H}$, Khodavaisy S, Haas PJ, et al. Molecular characterization and antifungal susceptibility testing of Candida nivariensis from blood samples: an Iranian multicentre study and a review of the literature. J Med Microbiol. 2019;68(5):770-7.

13 Mashaly G, Shrief R. Candida glabrata complex from patients with healthcare-associated infections in Mansoura University hospitals, Egypt: distribution, antifungal susceptibility and effect of fluconazole and polymyxin B combination. Germs. 2019;9(3):125-32.

14 Figueiredo-Carvalho MH, Ramos LS, Barbedo LS, Chaves AL, Muramoto IA, Santos AL, et al. First description of Candida nivariensis in Brazil: antifungal susceptibility profile and potential virulence attributes. Mem Inst Oswaldo Cruz. 2016;111(1):51-8.

15 Morales-López S, Dudiuk C, Vivot W, Szusz W, Córdoba SB, Garcia-Effron G. Phenotypic and molecular evaluation of echinocandin susceptibility of Candida glabrata, Candida bracarensis, and Candida nivariensis strains isolated during 30 years in Argentina. Antimicrob Agents Chemother. 2017;61(7): e00170-17.

16 Sharma C, Wankhede S, Muralidhar S, Prakash A, Singh PK, Kathuria S, et al. Candida nivariensis as an etiologic agent of vulvovaginal candidiasis in a tertiary care hospital of New Delhi, India. Diagn Microbiol Infect Dis. 2013;76(1):46-50.

17 Khan Z, Ahmad S, Al-Sweih N, Joseph L, Alfouzan W, Asadzadeh M. Increasing prevalence, molecular characterization and antifungal drug susceptibility of serial Candida auris isolates in Kuwait. PLoS One. 2018; 13(4):e0195743.

18 Jamal WY, Ahmad S, Khan ZU, Rotimi VO. Comparative evaluation of two matrix-assisted laser desorption/ionization time-of-flight mass spectrometry (MALDI-TOF MS) systems for the identification of clinically significant yeasts. Int J Infect Dis. 2014;26:167-70.

19 Khan Z, Ahmad S, Al-Sweih N, Khan S, Joseph L, Alfouzan W, et al. Candida lusitaniae in Kuwait: Prevalence, antifungal susceptibility and role in neonatal fungemia. PLoS One. 2019;14(3):e0213532.

20 Asadzadeh M, Ahmad S, Hagen F, Meis JF, Al-Sweih N, Khan Z. Simple, low-cost detection of Candida parapsilosis complex isolates and molecular fingerprinting of Candida orthopsilosis strains in Kuwait by ITS region sequencing and amplified fragment length polymorphism analysis. PLoS One. 2015; 10(11):e0142880.

21 Asadzadeh M, Alanazi AF, Ahmad S, AlSweih N, Khan Z. Lack of detection of Candida nivariensis and Candida bracarensis among 440 clinical Candida glabrata sensu lato isolates in Kuwait. PLoS One. 2019; 14(10):e0223920.
22 Ahmad S, Khan Z, Asadzadeh M, Theyyathel A, Chandy R. Performance comparison of phenotypic and molecular methods for detection and differentiation of Candida albicans and Candida dubliniensis. BMC Infect Dis. 2012; 12:230.

23 Edgar RC. MUSCLE: multiple sequence alignment with high accuracy and high throughput. Nucleic Acids Res. 2004;32(5): 1792-7.

24 Kumar S, Stecher G, Tamura K. MEGA7: molecular evolutionary genetics analysis version 7.0 for bigger datasets. Mol Biol Evol. 2016; 33(7):1870-4.

25 Altschul SF, Gish W, Miller W, Myers EW, Lipman DJ. Basic local alignment search tool. J Mol Biol. 1990;215(3):403-10.

26 Schoch CL, Seifert KA, Huhndorf S, Robert V, Spouge JL, Levesque CA, et al. Fungal barcoding consortium; fungal barcoding consortium author list. Nuclear ribosomal internal transcribed spacer (ITS) region as a universal DNA barcode marker for fungi. Proc Natl Acad Sci U S A. 2012;109:6241-6.

27 Consortium OPATHY; Gabaldón T. Recent trends in molecular diagnostics of yeast infections: from PCR to NGS. FEMS Microbiol Rev. 2019;43:517-47.

28 Aznar-Marin P, Galan-Sanchez F, Marin-Casanova P, García-Martos P, Rodríguez-Iglesias M. Candida nivariensis as a new emergent agent of vulvovaginal candidiasis: description of cases and review of published studies. Mycopathologia. 2016;181(5-6):445-9.

29 Alcoba-Flórez J, Arévalo MP, González-Paredes FJ, Cano J, Guarro J, Pérez-Roth E, et al. PCR protocol for specific identification of Candida nivariensis, a recently described pathogenic yeast. J Clin Microbiol. 2005; 43(12):6194-6.

30 Romeo O, Scordino F, Pernice I, Lo Passo C, Criseo G. A multiplex PCR protocol for rapid identification of Candida glabrata and its phylogenetically related species Candida nivariensis and Candida bracarensis. J Microbiol Methods. 2009;79(1):117-20.

31 Enache-Angoulvant A, Guitard J, Grenouillet F, Martin T, Durrens P, Fairhead C, et al. Rapid discrimination between Candida glabrata, Candida nivariensis, and Candida bracarensis by use of a singleplex PCR. J Clin Microbiol. 2011;49(9):3375-9.

32 Hou X, Xiao M, Chen SC, Kong F, Wang H, Fan $\mathrm{X}$, et al. Identification of Candida glabrata complex species: use of Vitek MS RUO \& Bruker ClinproTools. Future Microbiol. 2018;13:645-57.

33 Borman AM, Muller J, Walsh-Quantick J, Szekely A, Patterson Z, Palmer MD, et al. Fluconazole resistance in isolates of uncommon pathogenic yeast species from the United Kingdom. Antimicrob Agents Chemother. 2019;63(8):e00211-19. 